\title{
Olive oil and cancer
}

\author{
By Sergio López, Yolanda M. Pacheco, Beatriz Bermúdez, Rocío Abia and \\ Francisco J.G. Muriana*
}

\author{
Cellular and Molecular Nutrition, Instituto de la Grasa, \\ Consejo Superior de Investigaciones Científicas, Seville, Spain \\ "Corresponding author: Dr. Francisco J.G. Muriana. Tel: +34 954611550 \\ Email: muriana@ig.csic.es
}

\section{CONTENTS}

1. INTRODUCTION

2. MEDITERRANEAN DIET AND CANCER

3. THE ROLE OF FATTY ACIDS FROM OLIVE OIL IN CANCER

3.1. Olive oil and breast cancer

3.1.1. Experimental data

3.1.2. Epidemiological data

3.2. Olive oil and colon cancer

3.2.1. Experimental data

3.2.2. Epidemiological data

3.3. Olive oil and prostate cancer

3.4. Olive oil and other cancers

4. THE ROLE OF MINOR COMPOUNDS FROM OLIVE OIL IN CANCER

4.1. Relationship between ROS and cancer

4.2. ROS scavenger activity of olive oil phenolics

4.3. Potential anticancer activity of olive oil phenolic compounds

4.4. Potential anticancer activity of olive oil sterols

4.5. Potential anticancer activity of olive oil tocopherols

4.6. Potential anticancer activity of olive oil squalene

4.7. Potential anticancer activity of olive oil carotenoids ACKNOWLEDGMENTS

REFERENCES

\section{RESUMEN}

\section{Aceite de oliva y cáncer.}

Numerosos estudios en los últimos años han determinado la existencia de una asociación entre las grasas procedentes de la dieta y el cáncer. Los ácidos grasos poliinsaturados (PUFA) de la familia $n-6$ pueden tener efectos proliferativos y angiogénicos, lo cual se debe en parte a que son especialmente sensibles a la peroxidación lipídica, formándose aldehídos que reaccionan con las bases del ADN y por lo tanto aductos exocíclicos con propiedades genotóxicas. Por el contrario, el consumo de dietas ricas en ácidos grasos monoinsaturados (MUFA) está relacionado con un menor riesgo de distintos tipos de cáncer. Si bien, los datos epidemiológicos no siempre concuerdan con los datos experimentales. Los componentes menores del aceite de oliva (extra virgen), fundamentalmente el hidroxitirosol y tocoferol, son antioxidantes y secuestradores de radicales libres. Pueden minimizar la cantidad de especies reactivas de oxígeno que se generan por la peroxidación lipídica y además los MUFA son menos sensibles a la oxidación, por lo que se reduce el daño del ADN.

PALABRAS-CLAVE: Aceite de oliva; Ácidos grasos monoinsaturados; Componentes menores; Antioxidantes; Fenólicos; Dieta Mediterránea

\section{SUMMARY}

\section{Olive oil and cancer.}

In the last years, numerous studies have examined the association of dietary fat and cancer. Polyunsaturated fatty acids (PUFA) from n-6 family display a strong promoting effect, this may be partially due to the especially prone to lipid peroxidation of PUFA that leads to formation of aldehydes, which react with DNA bases, forming genotoxic exocyclic etheno(epsilon)-adducts. On the contrary, there are growing evidences that monounsaturated oils, like olive oil, may be associated with a decreased risk of some cancers. However, the epidemiological data do not fully agree with the experimental ones previously published. Minor compounds from (extra virgin) olive oil, mainly phenolics like hydroxytyrosol and tocopherol, are antioxidants and radical scavenging. They can minimize the amount of reactive oxygen species (ROS) generated by fatty acid peroxidation and in the case of monounsaturated fatty acids (MUFA) the DNA damage can be reduced by a lower lipid peroxidation.

KEY-WORDS: Olive oil; Monounsaturated fatty acids; Minor compounds; Antioxidants; Phenolics; Mediterranean diet.

\section{INTRODUCTION}

Cancer develops when cells in a part of the body begin to grow out of control. Although there are many kinds of cancer, they all start because of out-of-control growth of abnormal cells. Normal body cells grow, divide, and die in an orderly fashion. If DNA damage occurs, it is repaired in most of the cases. Un-repaired DNA alterations can be fixed as mutations in proliferating cells only and mutations of very few strategic genes can induce tumour formation, the most relevant are those activating proto-oncogenes and inactivating tumour suppressor genes. A series of mutations and/or epigenetic changes is required to drive transformation of a normal cell into malignant tumour. The apparently unrestricted growth has to be accompanied by a mechanism preserving telomeres which otherwise shorten with succeeding cell divisions leading to growth arrest. The majority of cancers in humans are induced by carcinogenic factors present in our environment including our food.

Cancer usually forms as a tumour. Malignant tumours show a greater degree of anaplasia and 
have the properties of invasion and metastasis. Some cancers, like leukaemia, do not form tumours. Instead, these cancer cells involve the blood and blood-forming organs and circulate through other tissues where they grow. To invade the surrounding tissues epithelial tumour cells have to lose some adhesion molecules keeping them attached to each other and to produce enzymes able to dissolve the elements of the basement membrane. Benign (non-cancerous) tumours do not spread to other parts of the body and, with very rare exceptions, are not life threatening.

During the multistage process of carcinogenesis, only rarely selected cells could proceed through a series of molecular changes from one stage to the next one along the pathway leading them ultimately to the formation of malignant tumour. At each stage, the pathway leading to malignancy is only one of the possible routes and different natural anticancer defence mechanisms further diminishing cancer risk. The peculiarity of these defence mechanisms stems from the fact that actually the most effective of them seem to operate at the very early stage proceeding the formation of the neoplastic cell. The examples given below could illustrate the issue (Jakobisiak et al., 2003):

- Many chemical carcinogens as well as ionizing and ultraviolet radiation are carcinogenic mainly through the induction of reactive oxygen species (ROS) able to produce DNA damage. However, various natural substances, many of which are termed antioxidants, present in our food or synthesized in our organism inhibit the formation of, trap or decompose ROS preventing their carcinogenic activity.

- Toxic compounds, including carcinogens, entering our cells are detoxified by enzymes and/or are removed from target epithelial tissues by a group of membrane proteins.

- If the above-mentioned mechanisms do not prevent carcinogens from gaining access to genes, damage of DNA could occur.

- Damage of DNA is probably repaired in most of the cases.

- Even if unrepaired, DNA damage can produce mutations and neoplastic transformation of only a small number of cells, usually stem cells, because the remaining cells are differentiated, do not proliferate and are committed to death.

- Only mutations of very few critical genes can induce tumour formation, the most relevant are those activating proto-oncogenes and inactivating tumour suppressor genes.

- Not a single mutation but a series of mutations and epigenetic changes is required to drive transformation of a normal cell into a malignant one and into the tumour. It is estimated that four to six genetic changes are required for the formation of a malignant tumour in humans.

- Even if a given cell achieved an apparently unrestrained growth due to activation of appropriate proto-oncogenes and inactivation of some tumour suppressor genes, telomeres shorten progressively with succeeding cell divisions leading to growth arrest unless telomerase is activated.

- Tumour cannot develop beyond the size of 1-2 $\mathrm{mm}$ in diameter without the induction of angiogenesis.

- Invasion and dissemination of tumour cells is prevented by some natural mechanisms. As for epithelial cells, adhesion molecules keep them bound to each other and they usually lack the enzymes able to dissolve the basement membranes.

- Tumour cells invading the surrounding tissues and penetrating lymphatic and blood vessels to disseminate and to form metastases can be recognized and eliminated by the immune system.

\section{MEDITERRANEAN DIET AND CANCER}

The incidence of cancer overall in Mediterranean countries is lower than in Scandinavian countries and the United States. This is mostly accounted for by the lower incidence among Mediterranean countries of cancer of the large bowel, breast, endometrial, and prostate. These forms of cancer have been linked to dietary factors, particularly low consumption of vegetables and fruit, and to a certain extent, high consumption of meat. The traditional Mediterranean diet is characterized by high consumption of foods of plant origin, relatively low consumption of red meat, and high consumption of olive oil, which in several studies has been reported to be more beneficial against cancer than other forms of added lipids.

Cancer has been one of the main diseases of the last century, and nowadays many of them do not have solution yet. Some scientists say that this disease is a result of a degeneration of the own body when it is exposed to potential tumorigenic substances (environmental factors) defined broadly to include tobacco, pollution, alcohol or diet. Among these factors, unhealthy diet is more likely to affect personal cancer risk. Research shows that about one-third of all cancer deaths are related to dietary factors and lack of physical activity in adulthood.

In the last years, numerous studies have examined the association of dietary fat and cancer. For some cancer, mainly breast cancer, the results of these prospective studies have provided little support for an important influence of dietary fat intake (Willet, 2001). The role of dietary fat in other 
cancers is not as cleary defined, although it appears that associations of fat intake with colorectal cancer is specific to fat from animal sources or may be attributed to meat intake, rather than fat per se (Potter, 1996).

In models of breast and colon cancer, saturated fats such as beef fat or lard, display only a weak promoting effect, with the incidence of induced tumours being similar at intake levels of $40 \%$ and $10 \%$ of energy (Weisburger, 1997). On the other hand, n-6-PUFA rich oils display a strong promoting effect and this may be due to the especially prone to lipid peroxidation initiated and propagated by reactive oxygen species (ROS), leading to the formation of highly mutagenic exocyclic DNA adducts (Weisburger, 1997; Hong et al., 2000; Owen et al., 2000a).

Interestingly, there is increased evidence that monounsaturated oils are associated with a lower risk of some cancers, which agrees with the composition of (extra virgin) olive oil and the potential role of monounsaturated fatty acids (MUFA) and minor compounds protective against ROS.

\section{THE ROLE OF FATTY ACIDS FROM OLIVE OIL IN CANCER}

A review, by Lipworth et al. (2000), summarizes the association of olive oil intake with cancer risk in humans. The authors concluded that olive oil does not have the cancer-promoting potential of other fat types. However, additional studies will be required to confirm this hypothesis.

\subsection{Olive oil and breast cancer}

\subsubsection{Experimental data}

There are many reports in the last 30 years showing the effect of olive oil and other oils in animals. It is well known that is necessary a minimal intake of essential fatty acids in the form of linoleic acid $(18: 2 n-6)$ to assess the maximal tumorigenic response of saturated fatty acids (SFA) (Ip et al., 1985). Nevertheless, cancer promotion not only depends on the amount of fats, but also on the fatty acid composition of the fat (Cohen et al., 1986a). Other experiments comparing different oils from corn, safflower, coconut and olive indicated that olive oil is the lesser inducer of mammary tumours (Cohen et al., 1986b; Cohen, 1987).

One of the mechanisms to explain how MUFA (olive oil) and medium-chain SFA does not promote mammary tumorigenesis is recurrent and mainly related to the competitive interactions between these fatty acids and the arachidonic acid (20:4n-6) for the enzymes of the eicosanoid biosynthetic pathway. Another one is that MUFA are less prone to lipid peroxidation that requires two or more unsaturated bonds in the fatty acid molecule (Mataix et al., 1993;
Owen et al., 2000a). Therefore, the level of ROS is lower when dietary PUFA are replaced by MUFA and in turn, there is a decrease in the level of exocyclic DNA adducts.

\subsubsection{Epidemiological data}

It has been described that at least in Greece and Spain long-time consumption of olive oil is associated with decreased risk of breast cancer (Martin-Moreno et al., 1994; Trichopoulou et al., 1995), which is not true for n-6 PUFA (Hunter et al., 1996; Willet, 1997; Holmes, 1999). However, there are also contradictory epidemiological studies showing no beneficial effects derived from olive oil intake (Yu et al., 1990; Gaard et al., 1995; Yuan et al., 1995).

Recently, Sieri et al. (2004) evaluated the association between dietary patterns and risk of developing breast cancer in an Italian cohort (ORDET cohort). Women volunteers were recruited from 1987 to 1992 from residents in Varese province, northern Italy. Participants completed a semiquantitative food frequency questionnaire. Using nutritional data from 8984 women with an average follow up of 9.5 years and 207 incident cases of breast cancer. The authors found four dietary patterns, which explained $30 \%$ of the variance: salad vegetables (mainly consisting of raw vegetables and olive oil); western (mainly consisting of potatoes, red meat, eggs and butter); canteen (pasta and tomato sauce); and prudent (cooked vegetables, pulses, and fish, with negative loading on wines and spirits). After adjustment for potential confounders, only the salad vegetables pattern containing olive oil was associated with significantly lower (34-35\%) breast cancer incidence $(\mathrm{RR}=0.66$, $\mathrm{Cl}(95 \%)=0.47-0.95$ comparing highest with lowest tertile) with a significant linear trend $(P=0.016)$. Women with body mass index $<25$ had an even greater risk reduction in the highest tertile of the salad vegetables pattern ( $>50 \%$ less risk than the lowest tertile, $\mathrm{RR}=0.39, \mathrm{Cl}(95 \%)=0.22-0.69)$ with a significant trend $(P=0.001)$; whereas women with body mass index $>$ or $=25$ had no protective effect. These findings suggest that a diet rich in raw vegetables and olive oil protects against breast cancer.

\subsection{Olive oil and colon cancer}

\subsubsection{Experimental data}

Colorectal cancer is one of the most common causes of cancer death in industrialized western countries. Earlier studies have shown that dietary fatty acid composition is important in colorectal carcinogenesis (Reddy, 1988; 1992). The effect of 
fatty acids is different among different species. MUFA induce lesser bile acids than $n-6$ PUFA, which is associated to an increase of cholesterol formation. However, there are no differences between $n-3$ and $n-6$ PUFA on bile acid synthesis in vitro (Dommels et al., 2002), whereas in animal studies $n-3$ PUFA appear to protect against colorectal carcinogenesis and $n-6$ PUFA enhance tumorigenesis.

\subsubsection{Epidemiological data}

As with studies in breast cancer, all efforts to achieve a relationship between dietary fatty acids and colorectal cancer have failed. A combined analysis of 13 case-control studies indicated that there was essentially no association of intake of total, saturated, monounsaturated or polyunsaturated fats with the risk of colorectal cancer (Howe et al., 1997). In the last years, scientists have investigated the effect of long-chain $n-3$ PUFA (20:5n-3, eicosapentaenoic acid; 22:6n-3, docosahexaenoic acid) as the main fat in the diet (consuming large quantities of fish) in order to prevent not only colorectal cancer but coronary disease too (Woutersen et al., 1999; Hong et al., 2000), leaving aside the olive oil.

\subsection{Olive oil and prostate cancer}

The early studies suggested a positive association between prostate carcinogenesis and saturated fat intake. Many years later, it was published that death rates from prostate cancer was lower in areas with high olive oil consumption, such as Greece and Italy (Rose et al., 1992; Kushi et al., 1995). However, more recently results have tended to have null associations (Kolonel, 1996; Kushi et al., 2002). Kolonel suggests that the discrepancies in those results may be due to adjust association of prostate cancer with dietary fat intake.

\subsection{Olive oil and other cancers}

Studies in Mediterranean countries revealed an inverse relation between consumption of olive oil and cancer of the bladder (Gonzalez et al., 1990), stomach (Buiatti et al., 1989), urinary tract (Bitterman et al., 1991), lung (Fortes et al., 1995; 2003) and endometrial (Tzonou et al., 1996b). However, there is no association in single studies with olive oil and cancer of pharynx (Franceschi et al., 1991), ovarian (Tzonou et al., 1993), pancreas (Kalapothak et al., 1993) and oesophagus (Tzonou et al., 1996a).

\section{THE ROLE OF MINOR COMPOUNDS FROM OLIVE OIL IN CANCER}

Phenolic compounds, commonly referred to as polyphenols, are present in extra virgin olive oil.
They are a complex mixture of compounds that include 3,4-dihydroxyphenylethanol (hydroxytyrosol), 4-hydroxyphenylethanol (tyrosol), 4-hydroxyphenylacetic acid, protocatechuic acid, syringic acid, vanillic acid, caffeic acid and $p$-coumaric acid, among others. The concentration of the phenolic fraction in olive oil varies depending on the cultivar, climate, and degree of ripeness of the fruit, being the average concentration around $500 \mathrm{mg} / \mathrm{L}$ in extra virgin olive oil. These bioactive compounds are "extra-nutritional" constituents that exhibit powerful antioxidant activity. Of the various phenolic compounds of extra virgin olive oil, hydroxytyrosol seems to be among the most important (Brenes et al., 1999; Tuck et al., 2002). It is present in free form and as a constituent of complex molecules (e.g. oleuropein) in olives. Its in vitro antioxidant potency is greater than butylated hydroxytoluene (Wiseman et al., 1996). In addition, olive oil phenolics have greater antioxidant potency than other vegetable oils. Some studies have demonstrated favourable effects of phenolics on thrombosis and tumorigenesis and promotion.

\subsection{Relationship between ROS and cancer}

The importance of antioxidant activity of olive oil minor compounds lies in the growing evidence that ROS are involved in the aetiology of fat-related tumours. ROS production notably increases in cancerous tissues compared with the normal tissues (Owen et al., 2000b).

It is considered that $80-90 \%$ of all human cancers are environmentally induced (Jensen and Madsen, 1988 ) and $30--40 \%$ of them by carcinogens present in our diet (Clemens, 1991). They damage DNA directly by forming, covalent adducts either with DNA or indirectly after being activated from inactive procarcinogens or through ROS they induce. However, some carcinogens are not genotoxic but stimulate cell proliferation thus increasing the probability of spontaneous occurrence of errors during DNA replication. Finally, some chemical bonds, including those present in DNA, can disintegrate spontaneously under physiological conditions. As mentioned above, one of the peculiarities of the natural anticancer defence mechanisms is that they start operating at the stage preceding the formation of tumour cells. Among ROS are superoxide anion $\left({ }^{\circ} \mathrm{O}_{2}{ }^{-}\right)$, hydrogen peroxide $\left(\mathrm{H}_{2} \mathrm{O}_{2}\right)$, hydroxyl radical $\left(\mathrm{OH}^{\circ}\right)$, singlet oxygen $\left({ }^{1} \mathrm{O}_{2}\right)$, alkoxyl radical $\left(\mathrm{RO}^{\circ}\right)$, and peroxyl radical ( $\left.\mathrm{ROO}^{\circ}\right)$, with hydroxyl radical being the most active in damaging DNA. Oxidative damage may include single- and double-strand breaks, abasic sites, and a variety of alterations in every constituent of DNA. For example, oxidative damage to cytosine alone results in at least 40 modified derivatives (Polverelli and Teoule, 1974). 
ROS are also formed because of normal cellular respiration in mitochondria, by neutrophils and eosinophils in their defence against microorganisms and during metabolism of steroids and arachidonic acid. ROS produced by neutrophils probably participate in the carcinogenic effects of chronic inflammatory reactions.

\subsection{ROS scavenger activity of olive oil phenolics}

Phenolic compounds from extra virgin olive oil may directly scavenge some radical species by acting as chain-breaking antioxidants and suppress lipid peroxidation by recycling other antioxidants, such as $\alpha$-tocopherol, by donating a hydrogen atom to the tocopherol molecule. $\alpha$-Tocopherol also may contribute to the antioxidant effects of olive oil. It is commonly known that compounds, which share an orthodiphenolic structure, possess antioxidant activity and there are a number of the phenolics in olive oil, which possess this structure, namely hydroxytyrosol. ROS injuries result in a number of harmful effects: disturbed cell metabolism, morphological and ultrastructural changes, attack on the regulation pathways and, alterations in the differentiation, proliferation and apoptosis. The powerful antioxidant activity of phenolics suggests a protective role for (extra virgin) olive oil in a chronic disease, such as cancer.

The antioxidant activity of olive oil phenolics has been widely studied by assessing the bleaching of the stable 1,1-diphenyl-2-picrylhydrazyl radical (DPPH) in membranes. The model system consists of dimyristoylphosphatidylcholine/linoleic acid unilamellar vesicles and a water azo compound as a free radical generator. The mean scavenging concentration $\left(\mathrm{SC}_{50}\right)$ value of hydroxytyrosol and oleuropein has been described to be 20.51 and $25.22 \mu \mathrm{M}$, respectively (Saija et al., 1998). It appears that these differences were because hydroxytyrosol can serve as scavenger of aqueous peroxyl radicals near the membrane surface, while oleuropein acts also as a scavenger of chain-propagating lipid peroxyl radicals within membranes (Tuck and Hayball, 2002). Gordon et al. (2001) found SC $_{50}$ values of $26 \mu \mathrm{M}$ for hydroxytyrosol acetate and $12 \mu \mathrm{M}$ for oleuropein aglycone, both phenolic compounds contained in olive oil (Brenes et al., 1999).

Briante et al. (2001) discovered that the capacity of oleuropein aglycone, hydroxytyrosol, elenolic acid with closed ring and elenolic acid with open ring to inhibit the fatty acid peroxidation rate is related to the degree of unsaturation of fatty acids. The authors confirmed that oleuropein and hydroxytyrosol possess greater antioxidant capacity than elenolic acid in either form.
Owen et al. (2000a) showed that phenolic compounds present in (extra virgin) olive oil are potent inhibitors of free radical generation by the faecal matrix, suggesting a major role of phenolics is preventing colorectal cancer. The most potent compound inhibiting ROS action is (+)-1-acetoxypinoresinol $(0.91 \mathrm{mM})$ follows by hydroxytyrosol $(1.34 \mathrm{mM})$, secoiridoid-1 (1.62 mM), p-hydroxybenzoic acid (1.69 $\mathrm{mM})$ and other phenolic compounds from (extra virgin) olive oil. Almost all of these compounds have an $\mathrm{IC}_{50}$, similar to $\mathrm{SC}_{50}$, in a range of 0.9-3.2, and Trolox had the lowest activity (12.24 mM) (Owen et al., 2003).

Recent observations have revealed that phorbol ester (PMA)-stimulated macrophages from animals fed with (extra virgin) olive oil release less superoxide than cells from animals fed with fish oil (Moreno et al., 2001). Both diets decreased eicosanoid production compared with a corn oil diet. Furthermore, olive oil and fish oil diets increased nitric oxide production. Olive oil reduced arachidonic acid mobilization and the subsequent metabolism of eicosanoids, but only olive oil increased the nitric oxide ("NO)/ROS ratio. Tyrosol decreased ROS production in a concentration-dependent manner after PMA-stimulation (Moreno et al., 2003). However, $\beta$-sitosterol inhibited ROS $\left(\mathrm{O}_{2}^{-}\right.$and $\left.\mathrm{H}_{2} \mathrm{O}_{2}\right)$ production when $\beta$-sitosterol is incubated for several hours before PMA-stimulation. These effects were not observed with squalene. The above-mentioned treatments did not cause cytotoxicity. These data shed some light on the mechanism involved in the beneficial effects of a diet rich in (extra virgin) olive oil.

\subsection{Potential anticancer activity of olive oil phenolic compounds}

Epidemiological studies suggest that (extra virgin) olive oil may offer protection for some types of cancer. Olive oil phenolic compounds reduce ROS generated both during metabolism of fatty acids (Mataix et al., 1993; Owen et al., 2000a) and cancer cells (Owen et al., 2000b), or by the action of exogenous agents like UV-light and ionizing radiation (Budiyanto et al., 2000; Ichihashi et al., 2000; Awad et al., 2003a).

UV-light generates DNA damage products such as 8-hydroxy-deoxyguanosine (8-OHdG), cyclobutane pyrimidine dimmers (CPD) and (6-4) photoproducts. Studies in animals reveal that post-treatment with extra virgin olive oil painted immediately after UV irradiation delay the onset and reduce the number of skin cancer, but pre-treatment with extra virgin olive oil and pre/post-treatment with refined olive oil (no phenolics) neither retard nor reduce skin cancer formation in UV-irradiated animals (Budiyanto et al., 2000; Ichihashi et al., 


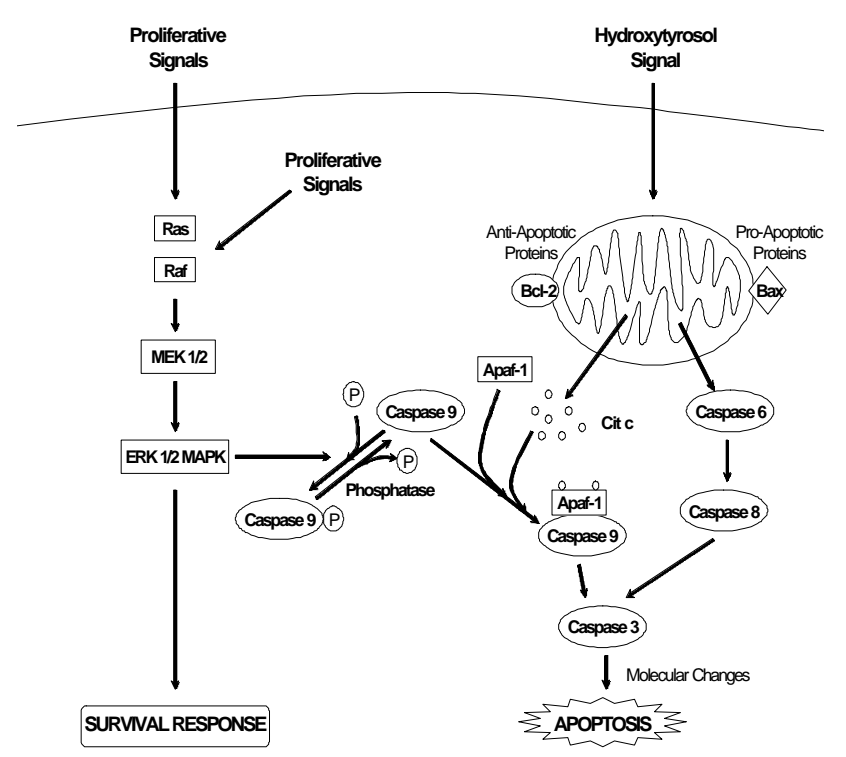

Figure 1

Apoptotic effects of hydroxytyrosol.

2000). These interesting findings indicate that minor compounds from olive oil have anticancer effects when tissues are damaged. The beneficial effect of extra virgin olive oil seems to be related with a decrease of 8-OHdG formation, with no effect on the levels of CPD and (6-4) photoproducts. A delay in the formation and yield of UV-induced skin cancer has been also described for animals treated with vitamin E acetate (Berton et al., 1998).

Hydroxytyrosol has been shown to be effective versus the human promyelocitic line HL60, but not on colorectal carcinoma cell lines Caco-2 and HT-29 (Ragione et al., 2000). Hydroxytyrosol, at a concentration of 50-100 $\mu \mathrm{M}$ (comparable with its content in extra virgin olive oil) caused a complete arrest of HL60 and induced apoptosis (Figure 1). There was an early release of cytochrome $\mathrm{c}$ from mitochondria, which precedes the activation of caspases 8 and 3 .

The human gingival malignant cell line $\mathrm{HSG}_{1}$ was sensitive to phenolics (Babich and Visioli, 2003). The sequence of increasing cytotoxicity was oleuropein aglycone>oleuropein glycoside, caffeic acid>o-coumaric acid>cinnamic acid>tyrosol, syringic acid, protocatechuic acid, vanillic acid. This effect was noted only at phenolic concentrations far exceeding those attainable after habitual consumption, thus indicating that consumption of phenol-rich olive oil is safe.

\subsection{Potential anticancer activity of olive oil sterols}

Phytosterols are considered anticancer dietary components (Moreno, 2003). Studies in human breast cancer cells have showed that $\beta$-sitosterol inhibits tumour cell invasion and cell growth by $70 \%$ compared with controls and induces cell cycle arrest at the $G_{2} / M$ phase (Awad et al., 2001). The mechanistic regulation of growth was through MAPK pathway (Awad et al., 2003a). Moreover, $\beta$-sitosterol induces apoptosis by the activation of caspases 8,9 and 3 (Awad et al., 2003b). $\beta$-Sitosterol may offer protection from breast cancer metastasis by inhibiting cell invasion of the basement membrane (laminin and collagen IV), which may be mediated by its ability to limit the adhesiveness of the tumour cells.

\subsection{Potential anticancer activity of olive oil tocopherols}

Gysin et al. (2002) investigated the effects of the $\alpha-, \beta-$, and $\gamma$-tocopherol on the growth of human prostate and colon cancer cells. They showed that although all of them inhibit the cell growth, was $\alpha$-tocopherol which strongest induced a significant growth inhibition (86\%) in androgen-independent prostate cancer cell line DU-145 (50\% by $\alpha$-tocopherol and $41 \%$ by $\beta$-tocopherol). Androgen-dependent prostate cancer cell line LNCaP was sensitive to tocopherols; cells grew only $26 \%$ relative to controls vs. $52 \%$ growth observed from $\alpha$-tocopherol-treated cells. The ability to proliferate of human colon adenocarcinoma (Caco-2) cells was reduced when treated with $\gamma$-tocopherol (64\%) and $\alpha$-tocopherol $(50 \%)$. Thus, inhibition of cell proliferation in DU-145, LNCaP, and Caco-2 cells was consistently inhibited more significantly by $\gamma$ - than by $\alpha$ - or $\beta$-tocopherol. Human osteosarcoma cell proliferation, on the other hand, was only weakly inhibited by $\gamma$-tocopherol, whereas proliferation of $\alpha$-tocopherol-treated cells was not distinguishable from that of controls. These observations were basically due to a decrease in the levels of cyclin D1 and E, and an increase in the levels of three cdk inhibitors (CKI): p21, p27 and p16 (Fiqure 2).

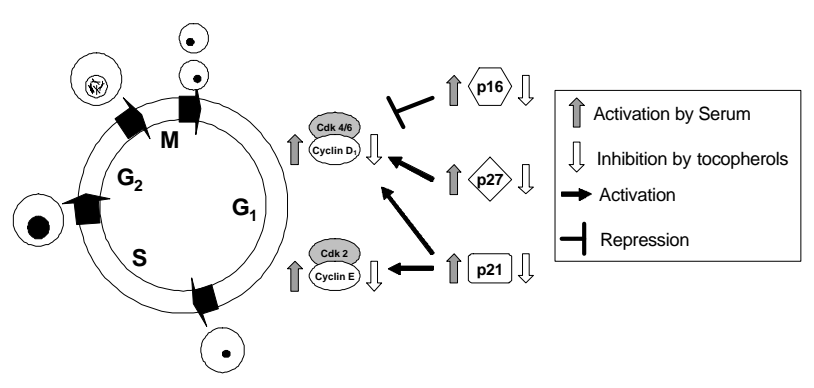

Figure 2

Tocopherols diminish protein levels for proteins important in G1-S transition, DNA synthesis and cell proliferation (adapted from Gysin et al., 2002). 
However, our body retains more $\alpha$-tocopherol than $\gamma$-tocopherol (Burton et al., 1998; Brigelius-Flohe et al., 1999). The biological antioxidant and non-antioxidant activities of $\alpha$-tocopherol are well known (Azzi et al., 2003; Villacorta et al., 2003), and $\gamma$-tocopherol has benefits by reducing the rate of sister chromatid exchange in humans (Elmadfa et al., 1999). Taken together, we can draw in mind a cellular mechanism supporting the concept emerging from epidemiological studies that a greater magnitude of risk reduction for prostate and colon cancer may occur if both total vitamin $\mathrm{E}$ consumption and the amount of $\gamma$-tocopherol in the diet are increased.

\subsection{Potential anticancer activity of olive oil squalene}

Squalene is an isoprenoid compound comprised of six isoprene units. The antioxidant property of squalene may be related to these isoprene units. Olive oil contains $0.2-0.7 \%$ of squalene. The intakes of squalene in Mediterranean countries reach $200-400 \mathrm{mg} /$ day (Newmark, 1999; Smith, 2000), which could raise the plasma level of squalene to approximately $10 \mu \mathrm{M}$. Squalene may have chemopreventive activity against colon carcinogenesis (Rao et al., 1998; Newmark, 1999). Its mechanism of action lies on the strong inhibition of 3-hydroxy-3-methylglutaryl coenzyme A (HMG-CoA) reductase activity, which reduces the availability of farnesyl pyrophosphate for the phenylation of the ras oncogene.

Experiments in animals show that consumption of squalene significantly inhibits the formation of colonic crypt foci (ACF) by 46\% (Rao et al., 1998) and lung hyperplasia by $70 \%$ (Smith et al., 1998). Normal human bone marrow (BM) derived colony-forming unit (CFU) growth can be increased by squalene in a dose-dependent manner (Das et al., 2003). Squalene $(12.5-25 \mu \mathrm{M})$ treatment significantly protected the CFUs from cisplatin-induced toxicity; the protective effect was equivalent to reduced glutathione (GSH). No evidence in humans has been discovered in vivo yet. There is an urgent need for the clinical development of safe and non-toxic cytoprotective agents for the adequate management of cancer chemotherapy. A phase I trial demonstrated that oral squalene is safe and tolerable (Chan et al., 1996). In the study, adult males were given $860 \mathrm{mg}$ of squalene daily for 20 weeks.

\subsection{Potential anticancer activity of olive oil carotenoids}

The major carotenoid compound in (extra virgin) olive oil is $\beta$-carotene, but also contains $\alpha$-carotene, lycopene, $\beta$-cryptoxanthin and lutein-zeaxanthin. More than a hundred of epidemiological studies have shown that people who consume more $\beta$-carotene (provitamin $A$ ) and have higher $\beta$-carotene levels in their blood have lower risk of cancer and particularly lung cancer (Nowak, 1994). Diet supplementation with $\beta$-carotene has been undertaken in two large clinical studies, but unexpectedly and tragically this supplementation resulted in the increased incidence of lung cancer in those smoking cigarettes (Omenn et al., 1996). We still do not know the final explanation.

A diet rich in lutein + zeaxanthin and long-chain PUFA may help to prevent human colon cancer (Nkondjock and Ghadirian, 2004). Lutein concentration in plasma is inversely associated with human cancer death (Mayne et al., 2004). Additionally, lycopene inhibits proliferation of tumoral cells (Olmedilla et al., 2001), and is a potential preventative in human prostate cancer (Klein and Thompson, 2004) and reduces risk of prostate, lung and digestive cancers (Tapiero et al., 2004).

\section{ACKNOWLEDGMENTS}

The authors would like to acknowledge to the Ministry of Education and Science (ECl) of the Spanish Government for supporting this manuscript (grant AGL2001-0584). Beatriz Bermúdez and Sergio López are supported by I3P and FPU fellowships, whereas Yolanda M. Pacheco has an I3P Post-Doctoral contract from ECI.

\section{REFERENCES}

Awad, A.B., Williams, H., Fink, C.S. (2001). Phytosterols reduce in vitro metastatic ability of MDA-MB-231 human breast cancer cells. Nutr. Cancer, 40, 157-164.

Awad, A.B., Williams, H., Fink, C.S. (2003a). Effect of phytosterols on cholesterol metabolism and MAP kinase in MDA-MB-231 human breast cancer cells. J. Nutr. Biochem., 14, 111-119.

Awad, A.B., Roy, R., Fink, C.S. (2003b). Beta-sitosterol, a plant sterol, induces apoptosis and activates key caspases in MDA-MB-231 human breast cancer cells. Oncol. Rep., 10, 497-500.

Azzi, A., Gysin, R., Kempna, P., Ricciarelli, R., Villacorta, L., Visarius, T., Zingg, J.M. (2003). The role of $\alpha$-tocopherol in preventing disease: from epidemiology to molecular events. Mol. Aspects Med., 24, 325-336.

Babich, H., Visioli, F. (2003). In vitro cytotoxicity to human cells in culture of some phenolics from olive oil. Farmaco, 58, 403-407.

Berton, T.R., Conti, C.J., Mitchell, D.L., Aldaz, M., Lubet, R., Fischer, S.M. (1998). The effect of vitamin E acetate on ultraviolet-induced mouse skin carcinogenesis. Carcinogenesis, 23, 175-184.

Bitterman, W.A., Farhadian, H., Abu Samra, C., Lerner, D., Amoun, H., Krapf, D., Makov, U.E. (1991). Environmental and nutritional factors significantly associated with cancer of the urinary tract among different ethnic groups. Urol. Clin. North Am., 18, 501-508.

Brenes, M., Garcia, A., Garcia, P., Rios, J.J., Garrido, A. (1999). Phenolic compounds in spanish olive oil. J. Agric. Food Chem., 47, 3535-3540. 
Briante, R., La Cara, F., Tonziello, M.P., Febbraio, F., Nucci, R. (2001). Antioxidant activity of the main bioactive derivates from oleuropein hydrolisis by hyperthermophilic beta-glycosidase. J. Agric. Food Chem., 49, 3198-3203.

Brigelius-Flohe, R., Traber, M.G. (1999). Vitamin E: function and metabolism. FASEB J., 13 1145-1155.

Budiyanto, A., Ahmed, N.U., Wu, A., Bito, T., Nikaido, O., Osawa, T., Ueda, M., Ichihashi, M. (2000). Protective effect of topically applied olive oil against photocarcinogenesis following UVB exposure of mice. Carcinogenesis, 21, 2085-2090.

Buiati, E., Palli, D., Decarli, A., Amadori, D., Avellini, C., Bianchi, S., et al. (1989). A case-control study of gastric cancer in Italy. Int. J. Cancer, 44, 611-616.

Burton, G.W., Traber, M.G., Acuff, R.V., Walters, D.N., Kayden, H., Hughes, L., Ingold, K.U. (1998). Human plasma and tissue alpha-tocopherol concentrations in response to supplementation with deuterated natural and synthetic vitamin E. Am. J. Clin. Nutr., 67, 669-684.

Chan. P., Tomlinson, B., Lee, C.B., Lee, Y.S. (1996). Effectiveness and safety of low-dose pravastatin and squalene, alone and in combination, in elderly patients with hypercholesterolemia. J. Clin. Pharmacol., 36, 422-427.

Clemens, M.R. (1991). Free radicals in chemical carcinogenesis. Klin. Wochenschr., 69, 1123-1134.

Cohen, L.A. (1987). Fat and endocrine-responsive cancer in animals. Prev. Med., 16, 468-474.

Cohen, L.A., Choi, K., Weisburger, J.H., Rose, D.P. (1986b). Effect of varying proportions of dietary fat on the development of $\mathrm{N}$-nitrosomethylurea.induced rat mammary tumours. Anticancer Res., 6, 215-218.

Cohen, L.A., Thompson, D.O., Maeura, Y., Choi, K., Blank, M.E., Rose, D.P. (1986a). Dietary fat and mammary cancer. I. Promoting effects of different dietary fats on $\mathrm{N}$-nitrosomethylurea rat mammary tumorigenesis. $\mathrm{J}$. Natl. Cancer Inst., 77, 33-42.

Das, B., Yeger, H., Baruchel, H., Freedman, M.H., Koren, G., Baruchel, S. (2003). In vitro cytoprotective activity of squalene on a bone marrow versus neuroblastoma model of cisplatin-induced toxicity. implications in cancer chemotherapy. Eur. J. Cancer, 39, 2556-2565.

Dommels, Y.E., Alink, G.M., Linssen, J.P., Van Ommen, B. (2002). Effects of $n-6$ and $n-3$ polyunsaturated fatty acids on gap junctional intercellular communication during spontaneous differentiation of the human colon adenocarcinoma cell line Caco-2. Nutr. Cancer, 42, 125-130.

Elmadfa, I., Park, E. (1999). Impact of diets with corn oil or olive/sunflower oils on DNA damage in healthy young men. Eur. J. Nutr., 38, 286-292.

Fortes, C., Forastiere, F., Anatra, F., Schmid, G. (1995). Consumption of olive oil and specific groups in relation to breast cancer risk in Greece. J. Natl. Cancer Inst., 87, 1020-1021.

Fortes, C., Forastiere, F., Farchi, S., Mallone, S., Trequattrinni, T., Anatra, F., Schmid, G., Perucci, C.A. (2003). The protective effect of the Mediterranean diet on lung cancer. Nutr. Cancer, 46, 30-37.

Franceschi, S., Bidoli, E., Baron, A.E., Barra, S., Talamini, R., Serraino, D., La Vecchia, C. (1991). Nutrition and cancer of the oral cavity and pharynx in north-east Italy. Int. J. Cancer, 47, 20-25.

Gaard, M., Tretli, S., Loken, E.B. (1995). Dietary fat and the risk of breast cancer: a prospective study of 25,892 Norwegian women. Int. J. Cancer, 63, 13-17.

Gonzalez, C.A., Torrent, M., Agudo, A. (1990). Dietary habits in Spain: an approximation. Tumori, 76, 311-314.
Gordon, M.H., Paiva-Martins, F., Almeida, M. (2001). Antioxidant activity of hydroxytyrosol acetate compared with that of other olive oil polyphenols. J. Agric. Food Chem., 49, 2480-2485.

Gysin, R., Azzi, A., Visarius, T. (2002). $\alpha$-Tocopherol inhibits human cancer cell cycle progresion and cell proliferation by down-regulation of cyclins. FASEB J., 16, 1952-1954.

Holmes, M.D., Hunter, D.J., Colditz, G.A., Stampfer, M.J., Hankinson, S.E., Speizer, F.E., Rosner, B., Willett, W.C. (1999). Association of dietary intake of fat and fatty acids with risk of breast cancer. JAMA, 281, 914-920.

Hong, M.Y., Lupton, J.R., Morris, J.S., Wang, N., Carrol, R.J., Davidson, L.A., Elder, R.H., Chapkin, R.S. (2000). Dietary fish oil reduces $0^{6}$-methylguanine DNA adduct levels in rat colon in part by increasing apoptosis during tumour initiation. Cancer Epidemiol. Biomarkers Prev., 9, 819-826.

Howe, G.R., Aronson, K.J., Benito, E., Castellano, R., Cornee, J., Duffy, S., et al. (1997). The relationship between dietary fat intake and risk of colorectal cancer: Evidence from the combined analysis of 13 case-control studies. Cancer Causes Control, 8, 215-228.

Hunter, D.J., Spiegelman, D., Adami, H.O., Beeson, L., Van den Brandt, P.A., Folsom, A.R., et al. (1996). Cohort studies of fat intake and the risk of breast cancer - a pooled analysis. N. Engl. J. Med., 334, 356-361.

Ichihashi, M., Ahmed, N.U., Budiyanto, A., Wu, A., Bito, T., Ueda, M., Osawa, T. (2000). Preventive effect of antioxidant on ultraviolet-induced skin cancer in mice. J. Dermatol. Sci., 23, S45-S50.

Ip, C., Carter, C.A., Ip, M.M. (1985). Requirement of essential fatty acid for tumorigenesis in the rat. Cancer Res., 45, 1997-2001.

Jakobisiak, M., Lasek, W., Golab, J. (2003). Natural mechanisms protecting against cancer. Immunol. Lett., 90, 103-22.

Jensen, H., Madsen, J.L. (1988). Diet and cancer. Review of the literature. Acta Med. Scand., 223, 293-304.

Kalapothaki, V., Tzonou, A., Hsieh, CC., Karakatsani, A., Trichopoulou, A., Toupadaki, N., Trichopoulos, D. (1993). Nutrient intake and cancer of the pancreas: a case-control study in Athens, Greece. Cancer Causes Control, 4, 383-389.

Klein, E.A., Thompson, I.M. (2004). Update on chemoprevention of prostate cancer. Curr. Opin. Urol., 14, 143-149.

Kolonel, L.N. (1996). Nutrition and prostate cancer. Cancer Causes Control, 7, 83-94.

Kushi, L.H., Lenart, E.B., Willet, W.C. (1995). Health implications of Mediterranean diets in light of contemporary knowledge. 2. Meat, wine, fats and oils. Am. J. Clin. Nutr., 61, 1416-1427.

Kushi, L., Giovannucci, E. (2002). Dietary fat and cancer. Am. J. Med., 113, 63S-70S.

Lipworth, L., Bailey, L.R., Trichopoulos, D. (2000). History of breast-feeding in relation to breast cancer risk: a review of the epidemiologic literature. J. Natl. Cancer Inst., 92, 302-312.

Mataix, J. (1993). Recent findings in olive oil research. Eur. J. Clin. Nutr., 47, 561-569.

Martin-Moreno, J.M., Willet, W.C., Gorgojo, L., Banegas, J.R., Rodriguez-Artalejo, F., Fernandez-Rodriguez, J.C., Maisonneuve, P., Boyle, P. (1994). Dietary fat, olive oil intake and breast cancer risk. Int. J. Cancer, 58, 774-780.

Mayne, S.T., Cartmel, B., Lin, H., Zheng, T., Goodwin, W.J. Jr. (2004). Low plasma lycopene concentration is 
associated with increased mortality in a cohort of patients with prior oral, pharynx or larynx cancers. J. Am. Coll. Nutr., 23, 34-42.

Moreno, J.J. (2003). Effect of olive oil minor components on oxidative stress and arachidonic acid mobilization and metabolism by macrophages raw 264.7. Free Radic. Biol. Med., 35, 1073-1081.

Moreno, J.J., Carbonell, T., Sanchez, T., Miret, S., Mitjavila, M.T. (2001). Olive oil decreases both oxidative stress and the production of arachidonic acid metabolites by the prostaglandin $\mathrm{G} / \mathrm{H}$ synthase pathway in rat macrophages. J. Nutr., 131, 2145-2149.

Newmark, H.L. (1999). Squalene, olive oil, and cancer risk. Review and hypothesis. Ann. N. Y. Acad. Sci., 889, 193-203.

Nkondjock, A., Ghadirian, P. (2004). Dietary carotenoids and risk of colon cancer: case-control study. Int. J. Cancer, 110, 110-116.

Nowak, R. (1994). Cancer prevention. Beta-carotene: helpful or harmful?. Science, 264, 500-501.

Olmedilla, B., Granado, F., Blanco, I. (2001). Carotenoides y Salud Humana. Fundación Española de la Nutrición (FEN).

Omenn, G.S., Goodman, G.E., Thornquist, M.D., Balmes, J., Cullen, M.R., Glass, A., Keogh, J.P., Meyskens, F.L., Valanis, B., Williams, J.H., Barnhart, S., Hammar, S. (1996). Effects of a combination of beta-carotene and vitamin A on lung cancer and cardiovascular disease. N. Engl. J. Med., 334, 1150-1155.

Owen, R.W., Giacosa, A., Hull, W.E., Haubner, R. Spiegelhalder, B., Bartsch, H. (2000a). The antioxidant/anticancer potential of phenolic compounds isolated from olive oil. Eur. J. Cancer, 36, 1235-1247.

Owen, R.W., Spiegelhalder, B., Bartsch, H. (2000b). Generation of reactive oxygen species by the faecal matrix. Gut, 46, 225-232.

Owen, R.W., Haubner, R., Hull, W.E., Erben, G., Spiegelhalder, B., Bartsch, H., Haber, B. (2003). Isolation and structure elucidation of the major individual polyphenols in carob fibre. Food Chem. Toxicol., 41, 1727-1738.

Polverelli, M., Teoule, R. (1974). Gamma irradiation of cytosine in an aerated aqueous solution. I. Identification of radiolysis products of cytosine resulting from the deamination pathway. $Z$. Naturforsch., 29, 12-15.

Potter, J.D. (1996). Nutrition and colorectal cancer. Cancer Causes Control, 7, 127-146.

Ragione, F.D., Cucciolla, V., Borriello, A., Pietra, V.D., Pontoni, G., Racioppi, L., Manna, C., Galleta, P., Zappia, V. (2000). Hydroxytyrosol, a natural molecule occurring in olive oil, induces cytochrome c-dependent apoptosis. Biochem. Biophys. Res. Commun., 278, 733-739.

Rao, C.V., Newmark, H.L., Reddy, B.S. (1998). Chemopreventive effect of squalene on colon cancer. Carcinogenesis, 19, 287-290.

Reddy, B.S. (1988). Overview of diet and colon cancer. Prog. Clin. Biol. Res., 279, 111-121.

Reddy, B.S. (1992). Dietary fat and colon cancer: animal model studies. Lipids, 35, 3388-3394.

Rose, D.P., Connolly, J.M. (1992). Dietary fat, fatty acids and prostate cancer. Lipids, 27, 798-803.

Saija, A., Trombetta, D., Tomaino, A., Lo Cascio, R., Princ., P., Uccella, N., Bonina, F., Castelli, F. (1998). In vitro evaluation of the antioxidant activity and biomembrane interaction of the plant phenols oleuropein and hydroxytyrosol. Int. J. Pharmaceut., 166, 123-133.
Sieri, S., Krogh, V., Pala, V., Muti, P., Micheli, A., Evangelista, A., Tagliabue, G., Berrino, F. (2004). Dietary patterns and risk of breast cancer in the ORDET cohort. Cancer Epidemiol. Biomarkers Prev., 13, 567-572.

Smith, T.J., Yang, G.Y., Seril, D.N., Liao, J., Kim, S. (1998). Inhibition of 4-(methylnitrosamino)-1-(3-pyridyl)1-butanone induced lung tumorigenesis by dietary olive oil and squalene. Carcinogenesis, 19, 703-706.

Smith, T.J. (2000). Squalene: potential chemopreventive agent. Expert Opin. Investig. Drugs, 9, 1841-1848.

Tapiero, H., Townsend, D.M., Tew, K.D. (2004). The role of carotenoids in the prevention of human pathologies. Biomed Pharmacother., 58, 100-110.

Trichopoulou, A., Katsouyanni, K., Stuver, S., Tzala, L., Gnardellis, C., Rimm, E., Trichopoulous, D. (1995). Consumption of olive oil and specific food groups in relation to breast cancer risk in Greece. J. Natl. Cancer Inst., 87, 110-116.

Tuck, K.L., Hayball, P.J. (2002). Major phenolic compounds in olive oil: metabolism and health effects. J. Nutr. Biochem., 13, 636-644.

Tuck, K.L., Hayball, P.J., Stupans, I. (2002). Structural characterization of the metabolites of hydroxytyrosol, the principal phenolic component in olive oil, in rats. $J$. Agric. Food Chem., 50, 2404-2409.

Tzonou, A., Hsieh, CC., Polychronopoulou, A., Kaprinis, G., Toupadaki, N., Trichopoulou, A., Karakatsani, A., Trichopoulos, D. (1993). Diet and ovarian cancer: a case-control study in Greece. Int. J. Cancer, 55, 411-414.

Tzonou, A., Lipworth, L., Garidou, A., Signorello, L.B., Lagiou, P., Hsieh, C., Trichopoulos, D. (1996a). Diet and risk of esophageal cancer by histologic type in a low-risk population. Int. J. Cancer, 68, 300-304.

Tzonou, A. Lipworth, L., Kalandidi, A., Trichopoulou, A., Gamatsi, I., Hsieh, C.C., Notara, V., Trichopoulou, D. (1996b). Dietary factors and the risk of endometrial cancer: a case-control study in Greece. Br. J. Cancer, 73, 1284-1290.

Villacorta, L., Graca-Souza, A.V., Ricciarelli, R., Zingg, J.M., Azzi, A. (2003). Alpha-tocopherol induces expression of connective tissue growth factor and antagonizes tumor necrosis factor-alpha-mediated downregulation in human smooth muscle cells. Circ. Res., 92, 104-110.

Weisburger, J.H. (1997). Dietary fat and risk of chronic disease: Mechanistic insights from experimental studies. Am. Diet Assoc., 97, S16-S23.

Willet, W.C. (1997). Specific fatty acids and risks of breast and prostate cancer: dietary intake. Am. J. Clin. Nutr., 66, 1557S-1563S.

Willet, W.C. (2001). Diet and breast cancer. J. Intern. Med., 249, 395-411.

Wiseman, A., Mathot, J.N., de Fouw, N.J., Tijburg, L.B.M. (1996). Dietary non-tocopherol antioxidants present in extra virgin olive oil increase the resistance of low-density lipoproteins to oxidation in rabbits. Atherosclerosis, 120, 15--23.

Woutersen, R.A., Appel, M.J., Van Garderen-Hoetmer, A., Wijnands, M.V. (1999). Dietary fat and carcinogenesis. Mutat. Res., 443, 111-127.

Yu, S.Z., Lu, R.F., Xu, D.D., Howe, G.R. (1990). A case-control study of dietary and nondietary risk factors for breast cancer in Shanghai. Cancer Res., 50, 5017-5021.

Yuan, J.M, Wang, Q.S., Ross, R.K., Henderson, B.E., Yu, M.C. (1995). Diet and breast cancer in Shanghai and Tianjin, China. Br. J. Cancer, 71, 1353-1358. 